\title{
Voluntary disclosure schemes for offshore tax evasion
}

\author{
Matthew Gould $^{1}$ (D) Matthew D. Rablen ${ }^{2,3}$ (D)
}

Published online: 4 January 2020

(c) The Author(s) 2020

\begin{abstract}
Tax authorities worldwide are implementing voluntary disclosure schemes to recover tax on offshore investments. The US and UK, in particular, have implemented such schemes in response to bulk acquisitions of information on offshore holdings, recent examples of which are the "Paradise" and "Panama" papers. Schemes offer affected investors the opportunity to make a voluntary disclosure, with reduced fine rates for truthful disclosure. Might such incentives, once anticipated by investors, simply encourage evasion in the first place? We characterize the investor/tax authority game with and without a scheme, allowing for the possibility that some offshore investment has legitimate economic motives. We show that a scheme increases net expected tax revenue, decreases illegal offshore investment and increases onshore investment, but could either increase or decrease legal offshore investment. The optimal disclosure scheme offers maximal incentives for truthful disclosure by imposing the minimum allowable rate of fine.
\end{abstract}

Keywords Voluntary disclosure $\cdot$ Offshore tax evasion · Tax amnesty $\cdot$ Third-party information

JEL Classification H26 · D85

Matthew D. Rablen

m.rablen@sheffield.ac.uk

Matthew Gould

matthew.gould@brunel.ac.uk

1 Department of Economics and Finance, Brunel University London, Cleveland Road,

Uxbridge UB8 3PH, UK

2 Department of Economics, University of Sheffield, 9 Mappin Street, Sheffield S1 4DT, UK

3 Tax Administration Research Centre, Exeter, UK 


\section{Introduction}

An estimated $10 \%$ of world GDP is held in tax havens, much, though by no means all, of which goes unreported (Zucman 2013; Alstadsæter et al. 2018). The loss of tax receipts due to offshore tax evasion by individuals in the United States (US) alone has been estimated at \$30-40 billion per annum (Gravelle 2009). In recent years, data breaches have allowed tax authorities around the world to acquire information on thousands of offshore investments. To recover any tax owing on these investments, tax authorities have, in many instances, offered affected investors a oneoff and time-limited opportunity to make a voluntary disclosure through a bespoke facility giving overt incentives for honesty (usually in the form of a lower fine rate). We term facilities of this form Incentivized Offshore Voluntary Disclosure Schemes, or just "schemes". The net revenues arising from such schemes have been significant: in 2009 a US scheme raised \$3.4 billion (GAO 2013) and a UK scheme netted nearly $£ 500$ million (Treasury Committee 2012). The UK scheme is estimated to have cost $£ 6$ million to administer (Committee of Public Accounts 2008), implying a return of $67: 1$. This compares favorably with reported yield/cost ratios in the UK of around 8:1 for traditional audit-based enforcement programs (HMRC 2006). ${ }^{1}$

The advent of offshore data leakages, and the associated implementation of voluntary disclosure schemes, may have come as a surprise to holders of legacy investments, but such developments are by now well understood by today's prospective offshore investors. Given that such schemes are by now largely anticipated, this raises the question of whether the continued use of such schemes is gainful to tax authorities. In particular, in offering incentives for voluntary disclosure, might such schemes simply encourage illegal offshore investment in the first place-a concern pointed to by some recent empirical evidence. We shed light on this concern.

In this paper, we appraise the use of anticipated offshore disclosure schemes using game theoretic tools. The model has two key features. First, we consider disclosure schemes that are implemented retrospectively in response to an information leak, as we argue characterizes practice in the UK and US. By the time of the information leak, however, the act of illegal offshore evasion has already taken place. As it cannot influence the illegal act retrospectively, the best a tax authority can do is seek to recover any tax owed. The importance of this observation lies in the fact that, in implementing incentivized schemes to recover efficiently tax owed from past evasion, the tax authority may inadvertently change the incentives for future acts of offshore evasion. Second, we recognize that there can be legitimate economic reasons for holding money in offshore accounts. Accordingly, not all investors who appear in data on offshore holdings owe tax. Pritchard and Khan (2005), the only published work we are aware of by tax authority insiders with unfettered access to the UK offshore data, reports that even among those entities flagged as the highest risk category in offshore data only $70 \%$ were expected to owe tax.

\footnotetext{
${ }^{1}$ The ratio of $8: 1$ is the estimated yield/cost ratio for self-assessment non-business enquiry work in 2005-2006.
} 
Why invest offshore if not to evade tax? As well as potential pecuniary benefits in the form of higher pre-tax rates of interest than available onshore, offshore investments can also offer legitimate tax advantages. Pension funds routinely invest via funds domiciled offshore, for they enable investors from different countries to invest in the same fund and can also legally prevent instances of double taxation. Most major onshore hedge funds have an accompanying offshore vehicle. For USbased tax-exempt organizations, such vehicles provide some legitimate relief from taxation of unrelated business income tax. As well as legitimate tax advantages, offshore investments potentially offer a range of non-pecuniary benefits: offshore providers are known to offer greater convenience and sophistication, presumably as they face lighter regulatory controls as compared with their onshore counterparts (Helm 1997). ${ }^{2}$ Recent leakages reveal that, in early 2000s, the Queen of the UK held around $£ 10$ million of her private money offshore: such investments had no tax motivation as the Queen is exempt from UK income and capital gains taxes. DEG, a development finance institution wholly owned by the German state, is known to have used offshore accounts for a number of years, citing non-pecuniary factors it utilized for legitimate operational purposes. ${ }^{3}$ Professional poker players, and other individuals who must transact regularly in many different currencies, are also known to make legitimate use of offshore bank accounts (O'Reilly 2007).

In order to appraise the impact of anticipated disclosure schemes, we first model the strategic interaction between investors and the tax authority in the absence of a scheme. ${ }^{4}$ We then introduce a scheme into the model and compare the results. An investor can decide to place an exogenous lump-sum either onshore or offshore. An onshore investment must be made legally, but an offshore investment may be made either legally or illegally. As such, not all investments tax authorities observe in offshore data owe tax. If an investor invests offshore, the investment is subsequently observed by the tax authority with a positive probability. In the absence of a scheme, if an investor's offshore investment is observed, the tax authority can, if it chooses, verify whether any tax is owed, but at a cost. Following verification of a tax liability, the tax authority can recover outstanding taxes and levy fines. An equilibrium of this game is inefficient to the extent that the tax authority struggles to achieve a credible threat to verify, owing to its inability to distinguish between legal and illegal offshore investments. In the presence of a scheme, the tax authority chooses an incentivized fine rate that will apply to liabilities disclosed within the scheme,

\footnotetext{
${ }^{2}$ Relative to their onshore counterparts in the US, Helm argues that offshore funds have greater flexibility and less procedural delays in changing the nature, structure, or operation of their products, and they face fewer investment restrictions, short-term trading limitations, capital structure requirements, and governance provisions. For evidence on the impact of these differences on the behavior of onshore and offshore financial institutions see Kim and Wei (2002).

3 See DEG (2015) wherein accounts held in Mauritius are disclosed on p. 57. For the operational justification see https://www.welt-sichten.org/artikel/32312/deg-ohne-offshore-geht-es-nicht .

${ }^{4}$ In this paper, we focus solely on efficiency. There is, however, an equity concern when offering incentives to tax evaders. Moreover, only a subset of evaders (i.e., those that evade through an offshore investment) benefit. See, e.g., Bordignon (1993) and Rablen (2010) for studies of the role of equity in influencing tax evasion. There are also moral and legal concerns concerning the purchase by tax authorities of information on offshore investments that was obtained by illegal means (see, e.g., Pfisterer 2013).
} 
and investors decide whether or not to make a disclosure within the scheme. If an investor does make a disclosure, they can either disclose their offshore investment to be illegal and pay the tax owed plus a fine at the incentivized rate, or disclose their investment as legal. The tax authority can choose to verify the investments of those investors who disclose their offshore investment to be legal (for an illegal investment might be falsely disclosed as legal). Even if an investor decides not to make a disclosure within the scheme, the tax authority can nevertheless choose to verify their investment and, where appropriate, levy fines.

We find that the introduction of a disclosure scheme induces fewer investors to invest offshore illegally. Key to this finding is the idea that disclosure schemes induce endogenous decisions by investors that act to lower the marginal cost of enforcement for tax authorities. Our findings imply that the number of investors investing onshore increases, but so too may the number investing offshore legally. Thus, our model suggests that empirical evidence pointing to increased offshore investment following the introduction of a scheme may not be evidence that such schemes generate additional offshore evasion, but instead evidence that such schemes generate additional legal offshore investment. Tax authorities also benefit from schemes: expected net revenue increases due to the additional voluntary compliance that occurs when some investors switch from investing offshore illegally to investing offshore legally. Consistent with the design of schemes in the UK, the model predicts that the optimal incentivized fine rate is the lowest allowable fine rate permitted in legislation.

The paper proceeds as follows: Sect. 2 gives an overview of the use and design of disclosure schemes in the recovery of offshore tax evasion, and Sect. 3 casts our contribution in the context of the existing literature. Section 4 presents the model, which is developed in the absence of a scheme in Sect. 5, and in the presence of a scheme in Sect. 6. Section 7 gives a comparative analysis of the consequences of the introduction of a scheme for investment behavior, welfare, and for net tax revenue; and Sect. 8 concludes.

\section{Offshore disclosure schemes}

Bulk leakages of offshore holdings data have in recent decades affected investors in almost all major economies: Table 1 in Langenmayr (2017), which summarizes and updates information provided in OECD (2010), documents the use of offshore voluntary disclosure schemes to address data leakages by 40 tax authorities worldwide. Leakages are occurring through a variety of channels. First, some tax authorities are aggressively exploiting legal powers that impel private financial institutions to release information relating to offshore holdings. Second, tax authorities are cooperating with whistleblowers. For instance, a list of offshore account holders of HSBC's Geneva branch — seized by French police in 2009- has been the subject of investigation by tax authorities worldwide, as are further lists published by the International Consortium of Investigative Journalists (the "Paradise" and "Panama" papers) 
and the Center for Public Integrity (Center for Public Integrity 2013). ${ }^{5}$ Third, tax authorities are exploiting information arising from new legislation, such as occurred when the 2003 European Savings Directive (European Union 2003) came into force. Last, tax authorities are taking steps to improve international cooperation through the signing of tax information exchange agreements, with the G20 countries leading in this regard. ${ }^{6}$ The creation in 2013 of an OECD Common Reporting Standard (OECD 2013) and, in 2010, the adoption in the US of the Foreign Account Tax Compliance Act (FATCA), are leading to continuing information flows regarding offshore investments. ${ }^{7}$

Some tax authorities have opted to address data leakages through standing generic mechanisms for voluntary disclosure, rather than implement bespoke offshore disclosure schemes. According to Table 1 of Langenmayr (2017), countries such as Australia, Canada, Germany and Japan have utilized standing mechanismsbut countries such as France, Israel, the UK, and the US have opted for bespoke schemes. In these latter set of countries, the impetus for each scheme may be traced to specific data leakages. For instance, one of the very first schemes, the 2007 Offshore Disclosure Facility (ODF), was implemented in the UK following legal action to force five major UK banks to disclose details of the offshore accounts held by their clients. The ODF offered affected investors time-limited access to a $10 \%$ fine rate (the minimum allowable penalty under UK civil legislation) if they made a full disclosure.

In 2009 the Internal Revenue Service (IRS) learned, via a whistleblower, details of the offshore accounts of a number of US citizens with the Swiss bank UBS. In response, it launched the Offshore Voluntary Disclosure Program (OVDP) in the same year and later implemented the Offshore Voluntary Disclosure Initiative in 2011. ${ }^{8}$ The UK implemented two schemes-the New Disclosure Opportunity and the Liechtenstein Disclosure Facility-in response to whistleblower information relating to (1) $100 \mathrm{UK}$ citizens with funds in Liechtenstein; and (2) all British clients of HSBC in Jersey (Watt et al. 2012). Following the signing of specific bilateral tax information exchange agreements, the UK implemented the 2009 Liechtenstein Disclosure Facility, and three further schemes aimed at its dependencies The Isle of Man, Jersey and Guernsey.

\footnotetext{
${ }^{5}$ A subset of the former list is the so-called "Lagarde list"-which contains 1991 names of Greeks with accounts in Switzerland. It was passed to the Greek authorities in 2010 by the then French Finance Minister, Christine Lagarde (Boesler 2012).

${ }^{6}$ Within eight months of the G20 summit of April 2009 tax havens had signed more than 300 treaties (Johannesen and Zucman 2014). See Konrad and Stolper (2016) for a more general model of the problem of coordinating against tax havens.

${ }^{7}$ For more on the economic impact of FATCA see Dharmapala (2016).

${ }^{8}$ See Table 1 and Appendix II of GAO (2013) for a full account of the background to, and operation of, these two schemes.
} 


\section{Literature review}

To our knowledge, the only theoretical analysis dedicated to offshore disclosure schemes is found in Langenmayr (2017). In her model, the tax authority is a first mover, deciding on the incentivized fine rate before investors decide whether or not to evade tax. Treating the tax authority as a first mover is appropriate to modeling the implementation of schemes in those countries which have chosen to handle offshore data acquisitions through standing generic mechanisms for voluntary disclosure. To our knowledge, however, no existing analysis addresses practice in, e.g., the UK and US, which-as discussed previously- have implemented bespoke schemes in reaction to specific data leakages. ${ }^{9}$ We address this lacuna: in our analysis the tax authority is assumed to move after investors have made their investment choice. This case is of interest as when the tax authority is endowed with the advantage associated with moving first an optimal scheme cannot lower net revenue, but when the first-mover advantage is handed to investors the desirability of such schemes is not a priori obvious.

Two other differences relative to Langenmayr's study are worthy of mention. First, Langenmayr finds the introduction of a scheme increases offshore tax evasion. This effect arises at the discretion of the tax authority as a consequence of its revenue-maximizing strategy. That is, in equilibrium, the tax authority "permits" an increase in evasion as the loss of revenue through voluntary compliance is more than recouped through additional fine payments. ${ }^{10}$ In our model, the tax authority takes evasion behavior as fixed, for it has already taken place when the scheme is conceived. In this context, these apparently perverse incentives on the part of the tax authority do not arise. Rather, we find that the introduction of a scheme unambiguously reduces illegal offshore evasion, albeit legal offshore investment could indeed be increased by a scheme. Second, while Langenmayr makes the important point that disclosure schemes may reduce the per-investor verification cost (as the investor freely supplies the necessary information) we show that a case for such schemes exists even neglecting this consideration. Instead, we highlight how the design of a scheme reduces the number of investments that must be verified. As a consequence, the marginal cost of increasing the probability of verification falls, for this probability applies to a smaller base of investments.

Our analysis relates to a number of other literatures. We connect to a literature on the use by tax authorities of pre-audit settlements in which investors can acquire full (e.g., Chu 1990; Glen Ueng and Yang 2001) or partial (Goerke 2015) insurance from audit risk. These settlements are shown to yield a Pareto improvement relative to random auditing as (1) the tax authority captures the positive risk premium of a

\footnotetext{
9 In assuming the tax authority moves second, our model has similarities with, e.g., Graetz et al. (1986). Different from this analysis, however, we assume that, for the tax authority to go to the trouble of performing verification, it must be strictly gainful in expectation. This leads the tax authority to adopt a pure strategy, whereas Graetz et al. consider a mixed strategy for the tax authority.

10 For another context in which a revenue-maximizing tax authority does not maximize voluntary compliance see Rablen (2014).
} 
risk-averse investor and (2) the tax authority conducts fewer random audits. Such audit settlement schemes, however, rely on the tax authority moving first, before the investor makes the evasion choice. They are, therefore, not directly applicable in our framework. It is also notable that, even were we to allow the tax authority to move first, such settlement procedures would not induce a Pareto improvement in our framework. We consider risk neutral investors, so the tax authority is not able to extract a positive risk premium; and we assume the tax authority audits optimally with and without a scheme, which rules out random auditing. In particular, in our model the tax authority does not gain from a reduction in the number of audits it performs per se, as it only ever audits when it is strictly gainful in expectation to do so.

As our model examines both the initial decision by the investor to evade, as well as the investor's subsequent disclosure decision, it is closely associated with the literature investigating anticipated tax amnesties, by which we mean voluntary disclosure schemes run in the absence of new information, which nevertheless offer investors reduced penalties if they wish to disclose an illegal offshore investment [see, e.g., Bayer et al. (2015) and the references therein]. Empirical evidence demonstrates clearly that there exists a significant body of investors who will not disclose under an amnesty who will disclose under a scheme, presumably because the latter entails the credible threat of sanctions in the event of non-disclosure. Londoño-Vélez and Ávila-Mahecha (2018) document how participation in a pre-existing Colombian mechanism for voluntary disclosure increased more than eightfold following the publication of the Panama papers, while Johannesen et al. (2018) and Bethmann and Kvasnicka (2016) document similarly large effects on the use of standing voluntary disclosure mechanisms in the US and Germany, respectively, following offshore data leakages. Consistent with this evidence, the investors in our model would never make a voluntary disclosure in the absence of new information, but do make a disclosure when, following the receipt of information, a scheme is offered. Whereas the literature has cast doubt on the desirability to tax authorities of anticipated amnesties, our analysis of voluntary disclosure schemes arrives at more positive conclusions. An optimally designed scheme, even when anticipated, increases net revenue and reduces illegal offshore evasion.

Our work also connects to the literature on law enforcement with self-reporting (e.g., Kaplow and Shavell 1994). In this literature, truthful disclosure is induced by allowing those who report to pay a sanction equal to the certainty equivalent of the expected sanctions they would otherwise face by not self-reporting. The insights of Kaplow and Shavell are sufficient to establish that, if a tax authority moves first, then a scheme can always be made unambiguously beneficial: it can be chosen, for instance, to lower enforcement costs while holding incentives to commit evasion fixed. While our model also utilizes this insight, the key difference between our model and this literature is that the tax authority moves second, after the crime is committed. In this setting, it is unclear that the desirable properties of self-reporting when the law enforcer moves first are retained.

A further related literature is that on optimal auditing in the presence of signals (e.g., Scotchmer 1987; Macho-Stadler and Pérez-Castrillo 2002; Bigio and Zilberman 2011). Under a scheme both the very act of making a disclosure and its 
content are signals that the tax authority observes before deciding whether to verify (audit). Last, as the ability of tax authorities to extract revenue from whistleblower data influences the degree to which they should incentivize such behavior, our findings inform the literature on the optimal incentivization of whistleblowing (Yaniv 2001) and complement studies that analyze compliance in the presence of potential whistleblowers (Mealem et al. 2010; Bazart et al. 2014; Johannesen and Stolper 2017).

\section{Model}

In this section, we model offshore disclosure schemes as a strategic interaction between investors, who can invest either onshore or offshore, and the domestic tax authority.

Each investor $i$ belonging to the set $T$ receives a lump-sum $w_{i}>0$, unobserved by the tax authority. The lump-sum is distributed across investors according to the function $W:[\underline{w}, \bar{w}] \in \mathbb{R}_{>0} \mapsto(0,1]$. Each investor should, by law, declare the lumpsum for taxation at the (exogenous) marginal rate $\theta \in(0,1) .{ }^{11}$ We assume, however, that investors have three possible actions: (1) invest the lump-sum offshore without declaring it for domestic taxation (illegal offshore investment); (2) declare the lumpsum for domestic taxation and invest the remaining amount $[1-\theta] w$ offshore (legal offshore investment); or (3) declare the lump-sum for domestic taxation and invest the remainder onshore. In considering these actions, we stress that investing money offshore is not an illegal act: what makes an offshore investment illegal in our model is the failure to previously declare the source capital for domestic taxation. Amounts invested offshore earn a rate of return $r_{\mathrm{OFF}}>0$, and amounts invested onshore earn a rate of return $r_{\mathrm{ON}}>0 .{ }^{12}$ Investors consume the investment (plus earned interest), upon its maturity.

We shall assume, for simplicity, that interest income accruing from investment is untaxed. That is, we focus on the evasion of tax on the source capital rather than the evasion ("sheltering") of interest income. As well as giving tractability, we note that the former is of greater economic significance: the amount of source capital is typically many times the annual interest flow such that only when undeclared interest

\footnotetext{
11 Although fiscal policy is endogenous at the level of government, we treat it as exogenous to the tax authority. In government, responsibility for the collection of taxes is usually decoupled from the setting of fiscal policy - the former being considered an operational matter, the latter one of policy. For instance, in the US, responsibility for the collection of taxes resides with an operational bureau of the Department of the Treasury, the IRS, whereas responsibility for fiscal policy lies on the policy side of the Department- the Office of Tax Policy. This structure is mirrored in the UK between H.M. Treasury and its collection agency, H.M. Revenue and Customs (HMRC). For a good overview of research into delegated tax enforcement see, e.g., Sánchez and Sobel (1993).

12 In modeling $\left\{r_{\mathrm{ON}}, r_{\mathrm{OFF}}\right\}$ as exogenous positive constants, the model is agnostic as to the relative magnitude of these two quantities. Under additional assumptions regarding the separate structures of the onshore and offshore industries, an arbitrage relationship might be postulated to endogeneously relate these two quantities. Our results are robust to, but do not require, such an approach.
} 
has accrued over many years does the tax liability from this source become of a comparable magnitude to that on the undeclared capital. ${ }^{13}$

As discussed in the introduction, offshore investments may differ from onshore investments both in the pecuniary and non-pecuniary dimensions. We capture the former dimension through the separate rates of return, $r_{\mathrm{ON}}$ and $r_{\mathrm{OFF}}$; and the latter dimension, for each investor $i$, by a parameter $b_{i}>0$, where $b_{i}<1$ signifies that the non-pecuniary benefits to $i$ from investing offshore exceed those from investing onshore, while $b_{i}>1$ signifies the reverse. $b_{i}$ is independent of $w_{i}$, and is distributed across investors according to the function $B: \mathbb{R}_{>0} \mapsto(0,1]$.

An offshore investment (legal or illegal) is subsequently observed by the tax authority with probability $p \in(0,1) .{ }^{14}$ In the long run, $p$ is endogenous to the efforts of tax authorities in, e.g., improving international cooperation and incentivizing whistleblowing. We treat $p$ as exogenously determined, however, as in the short-run tax authorities must take it as fixed.

The underlying inference problem for the tax authority is as follows: if it observes an offshore investment of amount $y$, this could be the illegal investment of an investor with lump-sum $w=y$ or the legal investment of an investor with lump-sum $w=y /[1-\theta]$. While the simplicity of our model confers many advantages, one disadvantage is that it might lead the reader to underestimate the practical complexities to a tax authority of making this inference: investors affected by offshore schemes are, in most cases, high net-worth individuals with often extremely complex financial arrangements, frequently involving the use of intermediary trust structures that make mapping investments to their "beneficial owner" a prolonged and laborintensive process. For this demographic, the idea that the lump-sum-even when declared-will appear in a transparent and separately itemized form within the tax return of a known individual in a known tax year is in most cases unduly optimistic. Rather-as evidenced by the fact that tax authorities are routinely observed to seek external information from both the affected taxpayer and other financial institutions - tax authorities are typically unable to verify the legality of an investment solely on the basis of their internal information. Moreover, even once a lump-sum has been pinpointed, its nature (e.g., bequest, income, capital gain) must be established to verify that the correct tax was applied. Bearing these points in mind, we therefore suppose the tax authority must sink a verification $\operatorname{cost} c>0$ to reveal the nature of an offshore investment. ${ }^{15}$

\footnotetext{
13 See, e.g., Pritchard and Khan (2005) for a detailed discussion and empirical evidence on this point.

14 We assume, for simplicity, that the tax authority acquires offshore data at zero cost, as has often been the case historically. On occasions when payments have been made, the amounts involved-where known-appear relatively modest in relation to the revenue generated. Bradley Birkenfeld, a UBS employee who acted as an IRS informer, received a payment of \$104 million, but in the context of some $\$ 3.4$ billion raised by the resulting scheme (GAO 2013). HMRC is reported to have paid a former Liechtenstein bank employee a fee of just $£ 100,000$ for information regarding more than $£ 100$ million of offshore assets (Oates 2008). Clearly, however, any amount paid to acquire information must be set against the revenue accruing from a scheme.

15 In our analysis, the cost $c$ applies always, irrespective of whether an investor makes a voluntary disclosure. In Langenmayr (2017), by contrast, verification is assumed to cost the tax authority less if the investor makes a voluntary disclosure. As this alternative assumption adds to the case for disclosure schemes, its adoption only strengthens the case for schemes.
} 
If a tax liability is verified, the tax authority can levy a fine on the undeclared tax at a rate $f \in[f, \bar{f}]$, where the bounds on $f$ are interpreted as being specified in legislation. Standard arguments (e.g., Kaplow and Shavell 1994) ensure that a revenuemaximizing tax authority will choose $f=\bar{f}$. At the fine rate $\bar{f}$, the amount an investor must pay in tax and fines on a verified illegal investment $y$ is denoted by

$$
Q(\bar{f}, y)=\theta[1+\bar{f}] y .
$$

We make the following assumptions:

Assumption $1 Q(\bar{f}, \underline{w})>c$.

Assumption $2 p[1+\bar{f}]>1>p[1+f]$.

Assumption 1 may be interpreted as requiring the lump-sum $w$ to be sufficiently large that it is gainful for the tax authority to verify an offshore investment known to be illegal. Empirically, this assumption is very likely satisfied, for offshore investments are typically large. ${ }^{16}$ Moreover, observed offshore holdings that are too small to be gainfully investigated can be screened almost costlessly by the tax authority. Assumption 2 implies that, at the maximum fine rate, $\bar{f}$, it is not gainful (in expectation) to invest offshore illegally if the tax authority, conditional on observing the investment, will verify with certainty. If this inequality is not satisfied, illegal offshore investment is a one-way bet, for it pays even when the tax authority's enforcement is maximal. The second inequality in Assumption 2 is that, at the minimum fine rate, $f$, it is gainful to invest offshore illegally even if, conditional on observing the investment, the tax authority will verify with certainty. If this inequality is not met, the tax authority's enforcement is so strong that it can eliminate all offshore investment in the presence of a scheme. Note that Assumption 2 rules out the pure amnesty case $p=0$ in which there is no threat that an illegal offshore investment will subsequently be observed.

Investors behave so as to maximize expected consumption, while the tax authority behaves so as to maximize revenue (comprising voluntary compliance, recovered tax, and fines) net of enforcement costs. ${ }^{17}$ While the implied risk neutrality of the tax authority is standard, the risk neutrality of investors might seem restrictive. Allowing for risk-averse investors can only strengthen the case for voluntary disclosure schemes, however. In the absence of a scheme, risk-averse investors would pay a premium to insure against the risk associated with possible tax authority

\footnotetext{
16 According to Watt et al. (2012), the list of HSBC Jersey account holders obtained by HMRC in 2012 identifies 4388 investors holding $£ 699$ million in offshore current accounts, which implies an average holding of $£ 159,000$. The median account balance of more than 10,000 closed cases from the 2009 OVDP in the US is reported as $\$ 570,000$ in GAO (2013).

17 For simplicity, we eliminate intertemporal considerations by assuming a time preference rate of unity (for both investors and the tax authority). To the extent that tax authorities do care about the timing of tax receipts, not just their level, our results suggest that the implementation of a scheme is beneficial. This holds as we find schemes to increase voluntary compliance, implying that more tax is paid at the time the investment is made.
} 
verification. When a scheme is offered, however, investors can avoid uncertain verification by disclosing truthfully. In this way, the tax authority is able to capture the investor's risk premium within the scheme. To establish an economic case for the use of such schemes, therefore, it is sufficient to suppose risk neutral investors.

We denote the expected consumption from choosing an investment of type $k$ as $C_{k}$, where $k=\mathrm{ON}$ is for onshore investment, $k=L$ is for legal offshore investment, and $k=I$ is for illegal offshore investment. We can then partition the set $T$ into those investors that invest onshore, offshore legally, and offshore illegally, $T=T_{\mathrm{ON}} \cup T_{\mathrm{OFF}}=T_{\mathrm{ON}} \cup T_{\mathrm{I}} \cup T_{\mathrm{L}}$, where

$$
\begin{aligned}
T_{\mathrm{ON}} & =i: C_{\mathrm{ON}} \geq \max \left\{C_{\mathrm{L}}, C_{\mathrm{I}}\right\} ; \quad T_{\mathrm{OFF}}=i: C_{\mathrm{ON}}<\max \left\{C_{\mathrm{L}}, C_{\mathrm{I}}\right\} ; \\
T_{\mathrm{L}} & =i \in T_{\mathrm{OFF}}: C_{\mathrm{L}} \geq C_{\mathrm{I}} ; \quad T_{\mathrm{I}}=i \in T_{\mathrm{OFF}}: C_{\mathrm{L}}<C_{\mathrm{I}} .
\end{aligned}
$$

Conditional on having chosen to invest offshore, the probability that an investor who invests an amount $y$ chooses to do so illegally is denoted $\phi=\phi(y) \in[0,1]$. When the tax authority chooses its enforcement parameters $\phi(y)$ has already been chosen by investors. As, however, the tax authority does not observe $\phi(y)$, it must base its enforcement choices on its expectation of this quantity, which we denote by $\mathbf{E}(\phi(y))$.

\section{No scheme}

In order to appraise the use of disclosure schemes, we now model the "do nothing" benchmark case in which the tax authority does not offer a scheme (NS). The game in the absence of a scheme is set out in Fig. 1. At the outset, nature determines each investor's lump-sum, $w_{i}$, and his/her level of non-pecuniary benefit, $b_{i}$, but this action is unobserved by the tax authority. Next, investors make an investment choice as described previously. Offshore investors have their investment subsequently observed by the tax authority with probability $p$. If offshore holdings are not observed by the tax authority, any illegal offshore investment goes undetected with probability one, and the game ends. If offshore holdings are observed by the tax authority, it will verify each offshore investment with a probability $\alpha \in[0,1]$, known to taxpayers. It follows that expected investor consumption is given by

$$
\begin{gathered}
C_{\mathrm{ON}}=\left[b_{i}+r_{\mathrm{ON}}\right][1-\theta] w ; \\
C_{\mathrm{L}}=\left[1+r_{\mathrm{OFF}}\right][1-\theta] w ; \\
C_{\mathrm{I}}=\left[1+r_{\mathrm{OFF}}\right][w-p \alpha Q(\bar{f}, w)] ;
\end{gathered}
$$

where implicit in this formulation is that an investor holding an illegal offshore investment must, in the event of verification, repatriate some of their investment to meet the tax and fines payable, and does not, therefore, earn interest on this amount. Note from (2) and (3) that if $r_{\mathrm{ON}}=r_{\mathrm{OFF}}$ and $b_{i}=1$ then an investor is exactly 
indifferent between a legal offshore investment and an onshore investment. More generally, the balance of pecuniary and non-pecuniary benefits favors a legal offshore investment when $r_{\mathrm{OFF}}-r_{\mathrm{ON}}>b_{i}-1$.

The expected net revenue the tax authority will generate from the members of $T$ is given by:

$$
R_{\mathrm{T}}(\alpha ; \mathbf{E}(\phi))=\iint_{T_{\mathrm{ON}} \cup T_{\mathrm{L}}} \theta w \mathrm{~d} W \mathrm{~d} B+p R_{\mathrm{OFF}}(\alpha ; \mathbf{E}(\phi)),
$$

where the first term is the revenue generated through voluntary compliance, and the second term,

$$
R_{\mathrm{OFF}}(\alpha ; \mathbf{E}(\phi))=\iint_{T_{\mathrm{OFF}}}\{\mathbf{E}(\phi)[\alpha Q(\bar{f}, y)-c]-[1-\mathbf{E}(\phi)] \alpha c\} \mathrm{d} Y \mathrm{~d} B,
$$

is the expected net revenue from verifying investors in OFF. Here $Y(\cdot)$ denotes the distribution function of observed offshore investments. Importantly, as the second mover, the tax authority takes as pre-determined the investment decisions of the investors. Accordingly, choosing $\alpha$ to maximize $R_{\mathrm{T}}(\alpha ; \mathbf{E}(\phi))$ is equivalent to choosing $\alpha$ to maximize $R_{\mathrm{OFF}}(\alpha ; \mathbf{E}(\phi))$, i.e., the net revenue from verifying the investments of offshore investors. Differentiating $R_{\mathrm{OFF}}(\alpha ; \mathbf{E}(\phi))$ with respect to $\alpha$ we obtain

$$
\frac{\partial R_{\mathrm{OFF}}(\alpha ; \mathbf{E}(\phi))}{\partial \alpha}=\iint_{T_{\mathrm{OFF}}}[\mathbf{E}(\phi) Q(\bar{f}, y)-c] \mathrm{d} Y \mathrm{~d} B .
$$

Hence, when observing an offshore investment of amount $y$, the tax authority chooses

$$
\alpha(y ; \mathbf{E}(\phi))= \begin{cases}0 & \text { if } \mathbf{E}(\phi) \leq \frac{c}{Q(\bar{f}, y)} \\ 1 & \text { otherwise. }\end{cases}
$$

How is the tax authority's expectation $\mathbf{E}(\phi)$ formed? Although in any one instance the tax authority may under- or over-predict the true value of $\phi$, it seems appropriate to assume that, on average, the tax authority's beliefs regarding $\phi$ are correct. We suppose, therefore, that the tax authority forms a rational expectation $\mathbf{E}(\phi)=\phi$. Hence, (6) reduces to

$$
\alpha(y ; \phi)= \begin{cases}0 & \text { if } \phi \leq \frac{c}{Q(\bar{f}, y)} \\ 1 & \text { otherwise }\end{cases}
$$

where here we adopt the convention that, if the tax authority is indifferent between verifying and not-verifying, it does not verify. Equation (7) captures an important intuition of the model: if the propensity to invest offshore illegally, $\phi$, is sufficiently high then the tax authority will always choose to verify $(\alpha=1)$. If, however, $\phi$, is sufficiently low that the expected gain from verification, $\phi Q(\bar{f}, y)-c$, falls to (or below) zero, the tax authority does not find it gainful to verify an observed offshore investment, hence $\alpha=0$. As shall become clear, the discreteness of the tax 
Fig. 1 The offshore evasion game in the absence of an offshore voluntary disclosure scheme

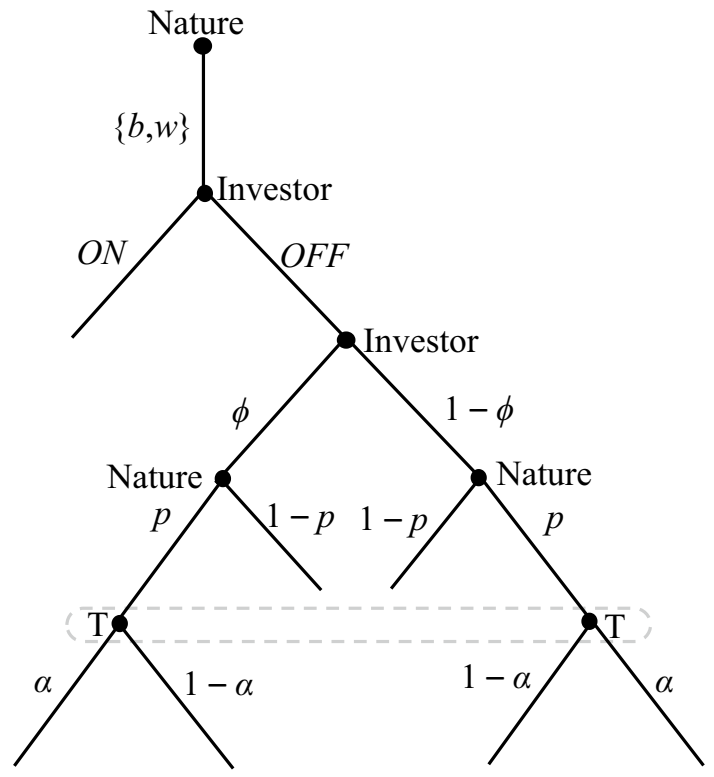

authority's verification strategy induces some risk neutral investors to commit offshore evasion probabilistically as part of a mixed strategy.

It follows from (7) that expected consumption, conditional on choosing to invest offshore, can be written as

$$
C_{\mathrm{OFF}}^{\mathrm{NS}}(\phi, w)= \begin{cases}{\left[1+r_{\mathrm{OFF}}\right]\{\phi w+[1-\phi][1-\theta] w\}} & \text { if } \phi \leq \frac{c}{Q(\bar{f}, w)} \\ {\left[1+r_{\mathrm{OFF}}\right]\{\phi[w-p Q(\bar{f}, w)]+[1-\phi][1-\theta] w\}} & \text { otherwise. }\end{cases}
$$

We depict $C_{\mathrm{OFF}}^{\mathrm{NS}}(\phi, w)$ as the solid line in Fig. 2. When $\phi \leq c / Q(\bar{f}, w)$ the investor's payoff in (8) is strictly increasing in $\phi$ for, from (7), the tax authority will choose not to verify. Immediately above $\phi=c / Q(\bar{f}, w)$ the tax authority becomes willing to verify, causing the payoff $C_{\mathrm{OFF}}^{\mathrm{NS}}$ to jump downward discretely. As a consequence of Assumption 2, once the tax authority can commit to verify, it is no longer gainful in expectation to invest offshore illegally. Accordingly, increases in $\phi$ above $c / Q(\bar{f}, w)$ are seen in Fig. 2 to only reduce the payoff $C_{\mathrm{OFF}}^{\mathrm{NS}}$ further. Thus, $C_{\mathrm{OFF}}^{\mathrm{NS}}$ is maximized with respect to $\phi$ where

$$
\phi(w)=\frac{c}{Q(\bar{f}, w)},
$$

at which point the tax authority is exactly indifferent between verifying and not-verifying.

Substituting (9) into (8) we obtain 


$$
C_{\mathrm{OFF}}^{\mathrm{NS}}(w)=\left[1+r_{\mathrm{OFF}}\right] \frac{c+[1-\theta][1+\bar{f}] w}{1+\bar{f}} .
$$

The payoff to investing offshore in (10) is strictly preferred to the payoff from investing onshore in (2) if

$$
b<\frac{C_{\mathrm{OFF}}^{\mathrm{NS}}(w)}{[1-\theta] w}-r_{\mathrm{ON}} \equiv \tilde{b}^{\mathrm{NS}}(w) .
$$

Proposition 1 In the absence of a scheme, if $b_{i}<\tilde{b}^{\mathrm{NS}}\left(w_{i}\right)$ an investor $i \in T$ invests offshore illegally with probability $\frac{c}{Q\left(\bar{f}, w_{i}\right)}$ and offshore legally with probability $\frac{Q\left(\bar{f}, w_{i}\right)-c}{Q\left(\bar{f}, w_{i}\right)}$; and invests onshore with probability one otherwise.

A hallmark of the equilibrium outcome is that, owing to its inability to distinguish between legal and illegal offshore investments, the tax authority is only able to cap the propensity for illegal offshore investment at $\phi\left(w_{i}\right)=c / Q\left(\bar{f}, w_{i}\right)$. Below this propensity it is unable to sustain a credible verification threat.

\section{The scheme}

We now suppose the tax authority offers a scheme in the event that offshore investments are observed. The game is set out in Fig. 3. The initial hidden action by nature and the subsequent investment decision are modeled in the same way as in the absence of a scheme. If offshore investments are observed, however, the tax authority chooses the terms of a scheme it then announces to investors. ${ }^{18,19}$ Investors then choose either to enter or not enter the scheme. If the investor enters $\mathrm{s} / \mathrm{he}$ discloses a type $d \in\{L, I\}$. An investor disclosing $d=I$ (illegal) accompanies their disclosure with a payment to the tax authority of $Q\left(f_{\mathrm{S}}, y\right)$, where $f_{\mathrm{S}} \in[\underline{f}, \bar{f}]$ is termed

\footnotetext{
${ }^{18}$ Thus an investor faces uncertainty as to whether their investment will be observed, but knows a scheme will be offered if their investment is observed. The model can be generalized to allow the tax authority to implement a scheme with a given probability in the event that information is observed. As, however, this probability turns out to be exactly one in equilibrium we omit this step without loss of generality.

${ }^{19}$ In practice a tax authority may also face a second choice as to the set of investors with whom it communicates the scheme. For instance, prior to the OVDP in the US, the Swiss authorities agreed to hand the IRS the names of approximately 4450 US clients with accounts at UBS. The IRS then had the choice of (1) requiring UBS to write to affected clients informing them that the details of their offshore holding had been handed to the IRS; or (2) requiring UBS to write to a wider set of its clients (up to the set of all UBS clients with offshore holdings) informing them that the details of their offshore holding might have been handed to the IRS. In actuality, the IRS chose the second option, and-to prevent investors from inferring whether their information had been handed over-negotiated a confidentiality clause with the Swiss that concealed the criteria by which the clients were selected until after the OVDP deadline had passed (GAO 2013). We abstract from this issue here, but note it as a potentially interesting avenue for future research.
} 


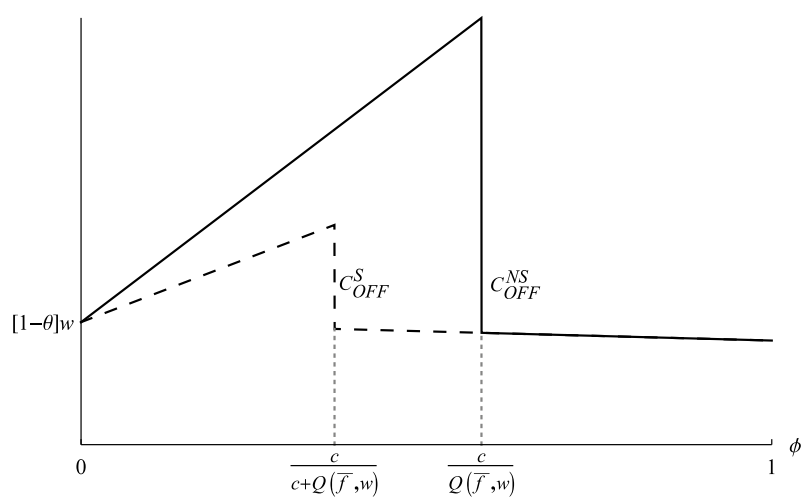

Fig. 2 Expected consumption as a function of $\phi$

the "incentivized" fine rate. An investor disclosing $d=L$ (legal) makes no accompanying payment. The tax authority verifies the disclosure $d=L$ with probability $\alpha_{\mathrm{S}} \in[0,1]$ and never verifies the disclosure $d=I$. Verification reveals the nature of an offshore investment with certainty: if the tax authority finds an investor to have disclosed falsely it levies a fine at the (maximum) rate $\bar{f}$. When an investor chooses to not enter the scheme the tax authority verifies their investment with probability $\alpha_{\mathrm{O}} \in[0,1]$. If an illegal investment is verified, the investor is fined at the rate $f_{\mathrm{O}} \in[f, \bar{f}]$. Standard arguments ensure that the tax authority will set $f_{\mathrm{O}}=\bar{f}$.

Owing to the revelation principle, attention may be confined to schemes (mechanisms) in which investors disclose truthfully. Consider the subgame that arises when an investor enters the scheme. If an investment is illegal, falsely disclosing $d=L$ results in an expected payment of $\alpha_{\mathrm{S}} Q(\bar{f}, y)$, whereas disclosing $d=I$ results in a sure payment of $Q\left(f_{\mathrm{S}}, y\right)$. Hence truthful disclosure requires that $Q\left(f_{\mathrm{S}}, y\right) \leq \alpha_{\mathrm{S}} Q(\bar{f}, y) .{ }^{20} \mathrm{As}$, in equilibrium, the tax authority will never find it optimal to set $f_{\mathrm{S}}$ below that required to achieve truthful disclosure, it follows that

$$
Q\left(f_{\mathrm{S}}, y\right)=\alpha_{\mathrm{S}} Q(\bar{f}, y) .
$$

If it observes the offshore investments the tax authority chooses the parameters of the scheme, $\left\{\alpha_{\mathrm{S}}, f_{\mathrm{S}}\right\}$, as well as the analogous parameters for investors who choose to not enter the scheme $\left\{\alpha_{\mathrm{O}}, f_{\mathrm{O}}\right\}$, to maximize the expected net revenue raised from investors belonging to $T_{\mathrm{OFF}}$. An investor with an illegal offshore investment faces a sure payment $Q\left(f_{\mathrm{S}}, w\right)=\alpha_{S} Q(\bar{f}, w)$ if they enter the scheme, and an expected payment $\alpha_{\mathrm{O}} Q(\bar{f}, w)$ if they choose to not enter. We assume that, in the case of perfect indifference, investors enter the scheme. Accordingly, an investor with an illegal offshore investment will enter the scheme if $\alpha_{\mathrm{O}} \geq \alpha_{\mathrm{S}}$. An investor with a legal offshore investment is indifferent between entering and not entering the scheme, so will always enter.

\footnotetext{
${ }^{20}$ If an offshore investment is legal, disclosing $d=I$ falsely results in a sure loss of $Q\left(f_{\mathrm{S}}, y\right)$, whereas disclosing $d=L$ results in no loss. Hence, truthful disclosure by investors in $T_{\mathrm{L}}$ is assured in equilibrium.
} 


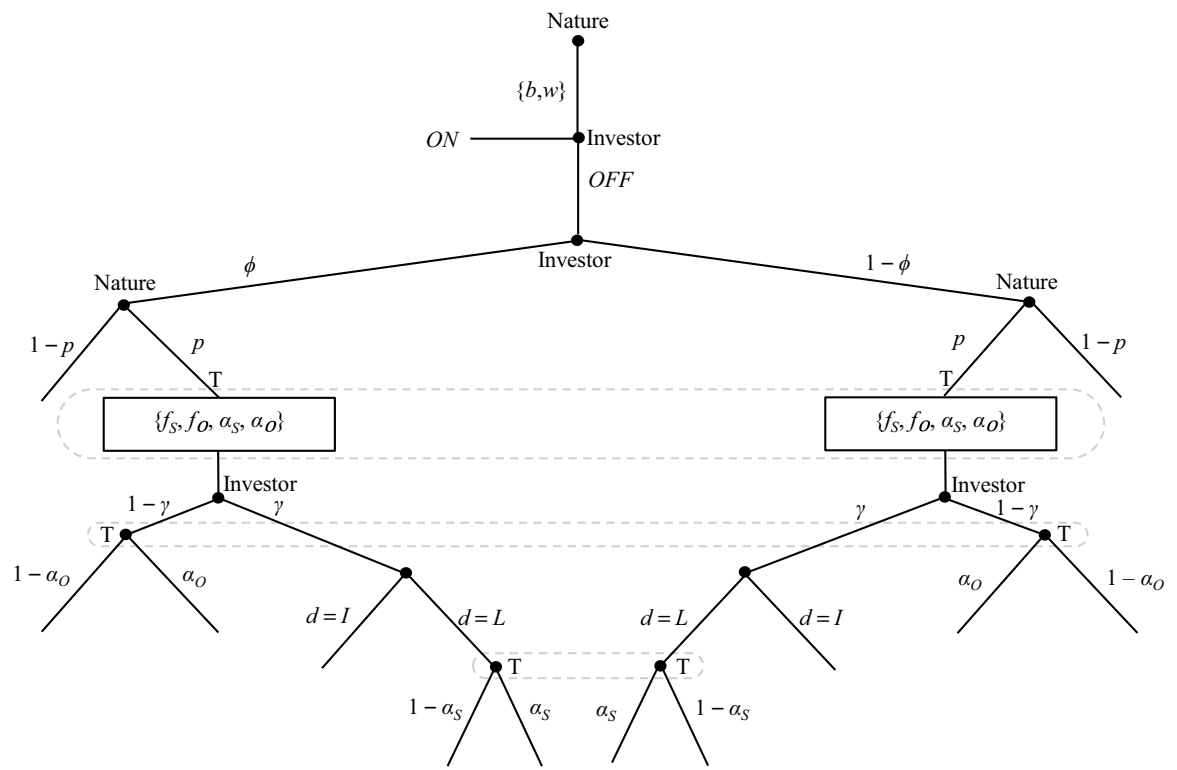

Fig. 3 The offshore evasion game in the presence of an offshore voluntary disclosure scheme

To emphasize a key intuition of the model, we focus on the (equilibrium) case in which investors choose to enter the scheme $\left(\alpha_{\mathrm{O}} \geq \alpha_{\mathrm{S}}\right)$. Using the equality in (11) expected net revenue generated within the scheme is

$$
\iint_{T_{\mathrm{OFF}}}\left\{\mathbf{E}(\phi) \alpha_{\mathrm{S}} Q(\bar{f}, y)-[1-\mathbf{E}(\phi)] \alpha_{\mathrm{S}} c\right\} \mathrm{d} Y \mathrm{~d} B .
$$

Focusing on the second term in the integral in (12), which is the cost of verification, note that the verification probability $\alpha_{\mathrm{S}}$ applies only to the expected proportion $1-\mathbf{E}(\phi)$ of offshore investors who have chosen to invest offshore legally, and therefore disclose $d=L$ (the remaining proportion $\mathbf{E}(\phi)$ of offshore investors who invest illegally disclose $d=I$ truthfully). Conversely, in the absence of a scheme, the verification probability $\alpha$ applies to all offshore investors. Expected verification costs therefore fall by a factor $[1-\mathbf{E}(\phi)]$ as fewer investments need to be verified. A consequence of this observation is that the expected marginal cost of increasing the verification probability also falls by a factor $[1-\mathbf{E}(\phi)]$ under a scheme. This, as we shall see, extends the set of values of $\phi$ for which the tax authority is able to maintain a credible verification threat in the presence of a scheme.

Establishing the equilibrium of the game in the presence of a scheme proceeds through the same set of steps as performed in Sect. 5. Matters are complicated only marginally by the existence of two distinct verification probabilities $\left\{\alpha_{\mathrm{O}}, \alpha_{\mathrm{S}}\right\}$ that are chosen by the tax authority simultaneously. In equilibrium, taxpayers again invest so as to make the tax authority indifferent between verifying 
and not-verifying, but-in light of the discussion above-this now occurs at a different threshold given by

$$
\phi^{\mathrm{S}}(w)=\frac{c}{c+Q(\bar{f}, w)} .
$$

The threshold value of value $b, \tilde{b}^{\mathrm{S}}(w)$, at which an investor is indifferent between investing onshore and offshore is then found as

$$
\tilde{b}^{\mathrm{S}}(w)=\frac{C_{\mathrm{OFF}}^{\mathrm{S}}(w)}{[1-\theta] w}-r_{\mathrm{ON}} .
$$

Relegating the proof to the Appendix, we arrive at the following:

Proposition 2 In the presence of a scheme, if $b_{i}<\tilde{b}^{\mathrm{S}}\left(w_{i}\right)$ an investor $i \in T$ invests offshore illegally with probability $\frac{c}{c+Q\left(\bar{f}, w_{i}\right)}$, and offshore legally with probability $\frac{Q\left(\bar{f}, w_{i}\right)}{c+Q\left(\bar{f}, w_{i}\right)} ;$ and invests onshore with probability one otherwise.

\section{Analysis}

\subsection{Verification}

A result that underlies all of the remaining findings we shall present is that the introduction of a scheme enhances the ability of the tax authority to sustain a credible threat to verify, leading to a lower threshold value of $\phi$ at which the tax authority becomes indifferent between verifying and not-verifying:

Proposition $3 \phi^{\mathrm{S}}(w)<\phi^{\mathrm{NS}}(w)$.

The underlying intuition for Proposition 3 is that, as noted previously, a scheme lowers the marginal cost of raising the verification probability. In particular, an increase in $\phi$ applies only to offshore investors who disclose $d=L$, whereas it applies to all offshore investors in the absence of a scheme. To ensure that verification is not gainful in expectation for the tax authority, investors therefore become obliged to invest offshore illegally with a lower probability.

\subsection{Investment and evasion: onshore and offshore}

By comparing the respective equilibria in the absence (Proposition 1) and presence (Proposition 2) of a scheme, we now analyze the consequences of introducing a scheme for both onshore and offshore investment volumes, and for the decomposition of offshore investments between those that are legal, and those that are illegal. 
Let us denote the expected proportion of investors choosing an investment type $m \in\{\mathrm{ON}, L, I\}$ as $\left|T_{\mathrm{m}}^{k}\right|$, where $k \in\{\mathrm{NS}, S\}$. Similarly, let $\left|m^{k}\right|$ denote the expected aggregate level of investment type $m$.

\section{Proposition 4}

(1) $\left|T_{\mathrm{OFF}}^{\mathrm{S}}\right|<\left|T_{\mathrm{OFF}}^{\mathrm{NS}}\right|$ and $\left|T_{\mathrm{ON}}^{\mathrm{S}}\right|>\left|T_{\mathrm{ON}}^{\mathrm{NS}}\right|$;

(2) $\left|T_{\mathrm{I}}^{\mathrm{S}}\right|<\left|T_{\mathrm{I}}^{\mathrm{NS}}\right|$ but $\left|T_{\mathrm{L}}^{\mathrm{S}}\right| \gtrless\left|T_{\mathrm{L}}^{\mathrm{NS}}\right|$;

(3) $\mathrm{OFF}^{\mathrm{S}}|<| \mathrm{OFF}^{\mathrm{NS}} \mid$ and $\left|\mathrm{ON}^{\mathrm{S}}\right|>\left|\mathrm{ON}^{\mathrm{NS}}\right|$;

(4) $\left|\mathrm{OFF}_{\mathrm{I}}^{\mathrm{S}}\right|<\left|\mathrm{OFF}_{\mathrm{I}}^{\mathrm{NS}}\right|$ but $\left|\mathrm{OFF}_{\mathrm{L}}^{\mathrm{S}}\right| \gtrless\left|\mathrm{OFF}_{\mathrm{L}}^{\mathrm{NS}}\right|$.

Parts (1) and (2) of Proposition 4 focus on the proportion of investors who invest offshore with and without a scheme. The proof of part (1) demonstrates that the enhanced verification threat present under a scheme causes a fall in the critical level of relative non-pecuniary benefits required to induce investors to invest onshore, i.e., $\tilde{b}^{\mathrm{S}}(w)<\tilde{b}^{\mathrm{NS}}(w)$. This implies that the introduction of a scheme induces a set of investors-those with characteristics belonging to the shaded set in Fig. 4-to switch from investing offshore to investing onshore. ${ }^{21}$

According to part (2), the introduction of a scheme also unambiguously reduces the proportion of investors who invest offshore illegally. As, however, both $T_{\mathrm{OFF}}$ and $T_{\mathrm{I}}$ shrink, the proportion of investors who invest offshore legally could either increase or decrease. In particular, if $T_{\mathrm{I}}$ shrinks proportionately more than does $T_{\mathrm{OFF}}$, then $T_{\mathrm{L}}$ expands. Parts (3) and (4) of Proposition 4 show that analogous results to those in parts (1) and (2) hold also for aggregate investment. In part (3) the introduction of a scheme causes aggregate investment to fall - simply because some investors switch from investing $w$ offshore illegally, to instead investing the reduced amount $[1-\theta] w$ onshore legally. The fall of total investment, coupled with an increase in onshore investment, implies that the offshore component of investment must fall. While the illegal component of offshore investment falls, the legal component may increase or decrease.

The possibility that the legal component of offshore investment could be observed to increase following the introduction of a scheme is consistent with the evidence of Langenmayr (2017), who observes an increase in officially recorded offshore investments by US citizens following the introduction of the 2009 OVDP. Within Langenmayr's framework - which does not allow for legal offshore investment-an increase in offshore investment can only be interpreted as an increase in illegal offshore evasion. Our model, which allows for legal offshore investment for legitimate economic purposes, offers an alternative interpretation of this finding.

\footnotetext{
21 The restriction that the density function $B$ takes strictly positive values for $w>0$ ensures that there will always exist a positive mass of investors belonging to the shaded space indicated in Fig. 4 .
} 
To gauge the size of the effects in Proposition 4 for realistic parameter values, we calibrate the model for the UK. ${ }^{22}$ Wealth is assumed to be lognormally distributed: $\log w \sim N(\mu, \sigma)$. The parameters $\{\mu, \sigma\}$ are estimated from the UK Wealth and Assets Survey as $\mu=8.90$, and $\sigma=1.91$. Non-pecuniary benefits are distributed according to the uniform ratio distribution, $b=X_{1} / X_{2}$, where $\left\{X_{1}, X_{2}\right\}$ are independent random variates with $X_{1} \sim U(0,2)$ and $X_{2} \sim U(0,2)$. Given the parameters of the wealth distribution, we use the average account balance of UK offshore investors in HSBC Jersey reported in Watt et al. (2012), i.e., £337,000, to estimate $\underline{w}=£ 85,655$. Combining this figure with the yield/cost ratio reported in footnote $\overline{1}$, we obtain $c=Q(1,337,000) / 8=£ 33,700$. The remaining parameters are set as $\theta=0.4, r_{\mathrm{OFF}}=r_{\mathrm{ON}}=0.05$, and $\bar{f}=1$.

For this calibration, we find that the introduction of a scheme is associated with a $3.3 \%$ increase in the proportion of investors choosing onshore, and a 5.8\% increase in the proportion of investors choosing to invest offshore legally. The proportion of investors choosing to invest offshore illegally falls by $26.5 \%$ (and the actual amount invested falls by $21.4 \%$ ).

\subsection{Tax revenue}

Does the introduction of a scheme increase the expected net revenue of the tax authority?

Proposition 5 The expected net revenue collected by the tax authority from the set of investors $T$ is increased by the introduction of a scheme: $R_{\mathrm{T}}^{\mathrm{S}}>R_{\mathrm{T}}^{\mathrm{NS}}$.

The intuition for Proposition 5 is that the increased propensity to invest legally raises the level of voluntary compliance. The increase in expected revenue from voluntary compliance is not offset by lower net revenues arising on amounts disclosed within the scheme (on account of the lower incentivized fine rate being applied). This occurs as the first-mover advantage enjoyed by investors permits them to make choices that leave the tax authority just indifferent between verifying and not-verifying. Hence, the expected revenue generated by verification activity is exactly offset by its cost.

Were we to have assumed that the tax authority could choose the scheme parameters before investors make their investment choice, the finding that net revenue increases under a scheme would be unsurprising. As, however, we take the tax authority to move second, the implications for net revenue were initially uncertain. It is notable, therefore, that even when moving second, voluntary disclosure schemes still increase net revenue. ${ }^{23}$

\footnotetext{
22 Similar estimates to those for the UK are obtained for the US when using wealth data from the Survey of Income and Program Participation of the US Census Bureau (Wealth and Asset Ownership section).

23 Whereas we consider a tax authority unfettered in its choice of fine rate from the interval $[f, \bar{f}]$, in many cases it is only in prescribed circumstances that a tax authority can levy the highest allowable fine rate. In the UK, for instance, the fine rate that applies is conditional upon the "behavioral" nature of the non-compliance: the lower bound applies if the non-compliance is judged to be through "careless error",
} 


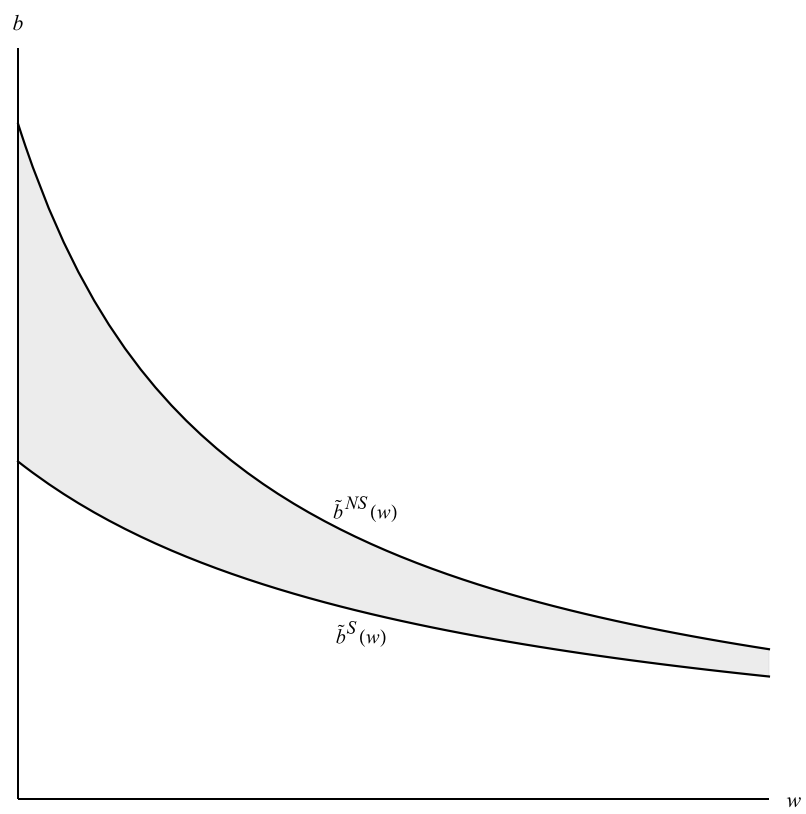

Fig. 4 The critical values $\tilde{b}^{\mathrm{NS}}(w)$ and $\tilde{b}^{\mathrm{S}}(w)$ at which an investor is indifferent between investing onshore or offshore

\subsection{Investor welfare}

We now examine the impact of a scheme for expected investor consumption (utility):

Proposition 6 For investors belonging to

(1) $T_{\mathrm{ON}}^{\mathrm{NS}} \cap T_{\mathrm{ON}}^{\mathrm{S}}, C^{\mathrm{NS}}=C^{\mathrm{S}}$;

(2) $T_{\mathrm{OFF}}^{\mathrm{NS}} \cap T_{\mathrm{OFF}}^{\mathrm{S}}, C^{\mathrm{NS}}>C^{\mathrm{S}}$;

(3) $T_{\mathrm{OFF}}^{\mathrm{NS}} \cap T_{\mathrm{ON}}^{\mathrm{S}}, C^{\mathrm{NS}}>C^{\mathrm{S}}$.

Part (1) of Proposition 6 is for investors who invest onshore irrespective of the provision of a scheme: such investors are wholly unaffected. Part (2) states that investors who invest offshore irrespective of the provision of a scheme lose consumption in the presence of a scheme. This loss arises as the probability $\phi^{\mathrm{S}}$ that an offshore investor chooses to invest illegally is lower in the presence of a scheme. Thus, the investor loses expected consumption on account of paying tax on the

\section{Footnote 23 (continued)}

whereas the upper bound applies to "deliberate and concealed" inaccuracies (HMRC 2012). A further potential benefit of schemes, therefore, is that they may provide the legal grounds to apply a higher rate of fine in cases where an investor either fails to respond to a disclosure opportunity, or makes a false disclosure within the scheme. 
lump-sum with a greater probability. Part (3) is for investors for whom the introduction of a scheme induces a switch from investing offshore to investing onshore. Such investors move from the higher payoff $C_{\mathrm{OFF}}^{\mathrm{NS}}$ in the absence of a scheme to the lower payoff $C_{\mathrm{ON}}$ in the presence of a scheme (continuing to invest offshore would yield the still lower payoff $C_{\mathrm{OFF}}^{\mathrm{S}}<C_{\mathrm{ON}}$ ). That those investing offshore illegally lose utility appears desirable - after all, it is a consequence of a reduction in incentives for breaking tax law. More generally, were we to model explicitly the benefits from taxation in the form of the public services it pays for, the increased tax revenue generated by schemes would generate utility for all investors through increased provision.

\subsection{Optimal incentivized fine rate}

For tax authorities seeking to understand the optimal design of disclosure schemes, it is of interest to highlight a feature of the optimal scheme relating to the question of how to set the incentivized fine rate for those that enter the scheme. We have the following result:

Proposition 7 In the optimal scheme, it holds that $f_{\mathrm{S}}=\underline{f}$.

According to Proposition 7, the incentivized fine rate is the lowest fine rate allowed under legislation. This is consistent with the design of disclosure schemes in the UK, which have offered those who disclose the minimum $10 \%$ penalty permitted in law. The Netherlands, for which $f=0$, implemented schemes in 2009 and 2013 on a no-fine basis. The result in Proposition 7 may initially seem surprising as choosing a lower fine rate reduces fine revenue. Although fine revenue indeed falls, net revenue is left unchanged. Lowering the incentivized fine rate makes truthful disclosure more attractive to investors, allowing the tax authority to achieve truthful disclosure with less verification. The reduction in verification costs achieved in this way exactly offsets the loss in fine revenue (as the tax authority is indifferent between verifying and not-verifying). Accordingly, the same level of net revenue is achieved with least verification activity by setting the incentivized fine rate minimally. ${ }^{24}$

\section{Conclusion}

Tax authorities around the world are using incentivized voluntary disclosure schemes to recover tax on offshore investments. Such schemes offer discounted fine rates for those who voluntarily disclose (albeit in the shadow of subsequent enforcement against those who do not). International initiatives such as the OECD Common Reporting Standard are expected to result in their continued use. As, however,

\footnotetext{
${ }^{24}$ A further factor that might account for the use of the minimum fine rate, albeit one that lies outside of our model, is the salience to investors of a low headline incentivized fine rate. For nascent studies of salience in the tax context see, e.g., Krishna and Slemrod (2003) and Chetty et al. (2009).
} 
the use of such schemes by tax authorities in response to data leakages is by now anticipated, the stellar returns observed for the earliest such schemes should not be expected to continue. As our model highlights, rational investors who anticipate being offered a scheme behave so as to make the tax authority indifferent between verifying offshore investments and not. In this paper, we examined whether indeed such anticipated schemes continue to be of value to tax authorities, or could actually be incentivizing offshore evasion in the first place.

We find that tax authorities can increase expected net revenue by implementing a disclosure scheme, rather than their regular verification regime. A hallmark of the optimal disclosure scheme is that it offers the minimum allowable fine rate in law to those that disclose truthfully. The particular benefit the implementation of a scheme affords tax authorities in our model is a reduction in the base of investments that require costly verification. This lowers the marginal cost of verification, permitting the tax authority a stronger threat to enforce tax law. Although the implementation of disclosure schemes is consistent with a rise in legal offshore investment, importantly our model predicts that the illegal component of offshore investment always falls. Thus, in a sense our model helps makes precise, it is possible to offer ex-post inducements for truthful disclosure without simply incentivizing the underlying criminal activity.

We offer the following suggestions for future research. First, one could extend the model to allow for the possible sheltering of interest in offshore accounts, alongside the possibility of tax evasion on the source capital. Second, imperfect verification technology might be allowed for, as in Rablen (2014). Third, communication between affected investors through a network, as in Hashimzade et al. (2014), might be introduced. Last, Johannesen et al. (2018) find that many US investors did not make use of the 2009 OVDP scheme but chose to make "quiet" disclosures through standing voluntary disclosure mechanisms following the leak of offshore data. The model could be extended to allow for this possibility as one of the investors' choices. While each of these avenues must await a dedicated treatment, we hope to have shed some further light on the economic effects and optimal design of disclosure schemes.

Acknowledgements We are grateful to an anonymous referee, Dominika Langenmayr, Duccio Gamannossi, Jacob Miethe, Damian Pritchard, David Rawlings, Jonathan Shaw, James Trees, Nick Warrington, Hubertus Wolff; and participants at the IIPF Annual Congress (Tampere), Royal Economic Society Conference (Bristol), EEA ESEM (Geneva, Cologne), LAGV 15 (Aix en Provence), the TARC Inaugural Workshop (Exeter), the IRS-TPC Research Conference (Washington, DC), PET 14 (Seattle) and the Shadow Economy International Conference (Münster) for very helpful comments. Rablen acknowledges gratefully financial support from the ESRC (ES/S00713X/1, ES/K005944/1, ES/K001744/1). For information relating to disclosure schemes in various countries, we thank Rohan Baxter (Australia), Duncan Cleary and Aisling Haughey (Ireland), Kurt Norell (Sweden) and Kim Bloomquist (United States).

Open Access This article is licensed under a Creative Commons Attribution 4.0 International License, which permits use, sharing, adaptation, distribution and reproduction in any medium or format, as long as you give appropriate credit to the original author(s) and the source, provide a link to the Creative Commons licence, and indicate if changes were made. The images or other third party material in this article are included in the article's Creative Commons licence, unless indicated otherwise in a credit line to the material. If material is not included in the article's Creative Commons licence and your intended use is not permitted by statutory regulation or exceeds the permitted use, you will need to obtain permission 
directly from the copyright holder. To view a copy of this licence, visit http://creativecommons.org/licen ses/by/4.0/.

\section{Appendix}

Proof of Proposition 1 The proof follows immediately from the arguments set out in the text.

Proof of Proposition 2 As discussed in the text, an investor with a legal offshore investment is indifferent between entering and not entering the scheme, so will enter. Given this, any investor who does not enter can be inferred to have invested illegally. Hence, by Assumption $1, \alpha_{\mathrm{O}}=1$. As $\alpha_{\mathrm{O}}$ is maximal, it must be that $\alpha_{\mathrm{O}} \geq \alpha_{\mathrm{S}}$, so, by the arguments in the text, illegal offshore investors will enter the scheme also. We may therefore write $R_{\mathrm{OFF}}\left(\alpha_{\mathrm{S}}, \alpha_{\mathrm{O}}, y ; \phi\right)$ as

$$
R_{\mathrm{OFF}}\left(\alpha_{\mathrm{S}}, y ; \phi\right)=\iint_{T_{\mathrm{OFF}}}\left\{\phi \alpha_{\mathrm{S}} Q(\bar{f}, y)-[1-\phi] \alpha_{\mathrm{S}} c\right\} \mathrm{d} Y \mathrm{~d} B .
$$

Differentiating $R_{\mathrm{OFF}}\left(\alpha_{\mathrm{S}}, y ; \phi\right)$ w.r.t. $\alpha_{\mathrm{S}}$ we obtain that

$$
\frac{\partial R_{\mathrm{OFF}}\left(\alpha_{\mathrm{S}}, y ; \phi\right)}{\partial \alpha_{\mathrm{S}}}=\iint_{T_{\mathrm{OFF}}}\{\phi Q(\bar{f}, y)-[1-\phi] c\} \mathrm{d} Y \mathrm{~d} B .
$$

If $\phi$ is sufficiently low, i.e., $\phi \leq c /[c+Q(\bar{f}, y)]$ then $\partial R_{\mathrm{OFF}}\left(\alpha_{\mathrm{S}}, y ; \phi\right) / \partial \alpha_{\mathrm{S}} \leq 0$, so the tax authority does not find it gainful to verify disclosures $d=L$. It follows that, in this case, $R_{\mathrm{OFF}}\left(\alpha_{\mathrm{S}}, y ; \phi\right)$ obtains a maximum at the lowest value of $\alpha_{\mathrm{S}}$ consistent with the truthtelling restriction $Q\left(f_{\mathrm{S}}, y\right)=\alpha_{\mathrm{S}} Q(\bar{f}, y)$. Hence $\alpha_{\mathrm{S}}=\underline{\alpha}_{\mathrm{S}}=[1+f] /[1+\bar{f}]$. If $\phi>c /[c+Q(\bar{f}, y)]$ then verification is strictly gainful, so $R_{\mathrm{OFF}}\left(\alpha_{\mathrm{S}}, y ; \bar{\phi}\right)$ achieves a maximum at $\alpha_{\mathrm{S}}=1$. Hence

$$
\begin{gathered}
\alpha_{\mathrm{O}}(y ; \phi)=1 ; \\
\alpha_{\mathrm{S}}(y ; \phi)= \begin{cases}\underline{\alpha}_{\mathrm{S}} & \text { if } \phi \leq \frac{c}{c+Q(\bar{f}, y)} \\
1 & \text { otherwise. }\end{cases}
\end{gathered}
$$

With the nature of enforcement now determined, we analyze the investor's investment decision. Expected consumption, conditional upon investing offshore illegally with probability $\phi \in[0,1]$, can be written using (15) as

$$
C_{\mathrm{OFF}}^{\mathrm{S}}(\phi, w)= \begin{cases}{\left[1+r_{\mathrm{OFF}}\right]\{\phi[w-p Q(f, w)]+[1-\phi][1-\theta] w\}} & \text { if } \phi \leq \frac{c}{c+Q(\bar{f}, w)} \\ {\left[1+r_{\mathrm{OFF}}\right]\{\phi[w-p Q(\overline{\bar{f}}, w)]+[1-\phi][1-\theta] w\}} & \text { otherwise. }\end{cases}
$$

Note that (17) uses the fact that, from (11), $f_{\mathrm{S}}=\bar{f}$ when $\phi>c /[c+Q(\bar{f}, w)]$, and $f_{\mathrm{S}}=f$ when $\phi \leq c /[c+Q(\bar{f}, w)]$. The shape of $C_{\mathrm{OFE}}^{\mathrm{S}}(\phi, w)$ as a function of $\phi$ is shown $\bar{a}$ s the dashed line in Fig. 2. For $\phi \leq c /[c+Q(f, w)]$ the investor's payoff 
is strictly increasing in $\phi$, by Assumption 2, as the tax authority will perform verification only with the fixed minimum probability $\underline{\alpha}_{\mathrm{S}}$. At $\phi=c /[c+Q(\bar{f}, w)]$ the investor's payoff initially falls discreetly, and becomes strictly decreasing in $\phi$ thereafter (by Assumption 2). It follows that $C_{\mathrm{OFF}}^{\mathrm{S}}(\phi)$ obtains a maximum in $\phi$ at $\phi(w)=c /[c+Q(\bar{f}, w)]$. Substituting this expression for $\phi$ into (17), equilibrium consumption when investing offshore is

$$
C_{\mathrm{OFF}}^{\mathrm{S}}(w)=\frac{\left[1+r_{\mathrm{OFF}}\right] w}{c+Q(\bar{f}, w)}\{c+[1-\theta] Q(\bar{f}, w)\} .
$$

The payoff $C_{\mathrm{OFF}}^{\mathrm{S}}(w)$ in (18) to investing offshore is strictly preferred to the payoff from investing onshore in (2) if $b<\tilde{b}^{\mathrm{S}}(w)$, where $\tilde{b}^{\mathrm{S}}(w)$ is given in (14). The Proposition follows.

Proof of Proposition 3 We have

$$
\phi^{\mathrm{S}}(w)=\frac{c}{c+Q(\bar{f}, w)}<\frac{c}{Q(\bar{f}, w)}=\phi^{\mathrm{NS}}(w) .
$$

Proof of Proposition 4 The expected proportion of investors with lump-sum $w$ who invest offshore legally, $\tau_{\mathrm{L}}(w)$, and illegally, $\tau_{\mathrm{I}}(w)$, are given, respectively, by

$$
\tau_{\mathrm{L}}^{k}(w)=\left[1-\phi^{k}\right] B\left(\tilde{b}^{k}(w)\right) ; \quad \tau_{\mathrm{I}}^{k}(w)=\phi^{k} B\left(\tilde{b}^{k}(w)\right) ;
$$

where $k \in\{N S, S\}$, and $\phi^{k}$ is the value of $\phi$ in state $k$. Hence, in aggregate, the expected proportions of investors choosing each investment type are given by

$$
\begin{array}{ll}
\left|T_{\mathrm{ON}}^{k}\right|=\int\left[1-\tau_{\mathrm{L}}^{k}(w)-\tau_{\mathrm{I}}^{k}(w)\right] \mathrm{d} W ; & \left|T_{\mathrm{OFF}}^{k}\right|=\int\left[\tau_{\mathrm{L}}^{k}(w)+\tau_{\mathrm{I}}^{k}(w)\right] \mathrm{d} W ; \\
\left|T_{\mathrm{L}}^{k}\right|=\int \tau_{\mathrm{L}}^{k}(w) \mathrm{d} W ; & \left|T_{\mathrm{I}}^{k}\right|=\int \tau_{\mathrm{I}}^{k}(w) \mathrm{d} W .
\end{array}
$$

Expected aggregate net onshore and offshore investment are given by

$$
\begin{aligned}
\left|\mathrm{ON}^{k}\right| & =[1-\theta] \int w\left[1-B\left(\tilde{b}^{k}(w)\right)\right] \mathrm{d} W \\
\left|\mathrm{OFF}^{k}\right| & =\int w\left\{1-\theta\left[1-\phi^{k}(w)\right]\right\} B\left(\tilde{b}^{k}(w)\right) \mathrm{d} W
\end{aligned}
$$

where the latter may be further decomposed into its legal and illegal components:

$$
\begin{aligned}
\left|\mathrm{OFF}_{\mathrm{I}}^{k}\right| & =\int w \phi^{k}(w) B\left(\tilde{b}^{k}(w)\right) \mathrm{d} W \\
\left|\mathrm{OFF}_{\mathrm{L}}^{k}\right| & =[1-\theta] \int w\left[1-\phi^{k}(w)\right] B\left(\tilde{b}^{k}(w)\right) \mathrm{d} W .
\end{aligned}
$$

Next, we establish that $\tilde{b}^{\mathrm{S}}(w)<\tilde{b}^{\mathrm{NS}}(w)$ : 


$$
\begin{aligned}
\tilde{b}^{\mathrm{S}}(w)<\tilde{b}^{\mathrm{NS}}(w) & \Leftrightarrow \frac{c+[1-\theta] Q(\bar{f}, w)}{c+Q(\bar{f}, w)}<\frac{\theta c+[1-\theta] Q(\bar{f}, w)}{Q(\bar{f}, w)} ; \\
& \Leftrightarrow \frac{Q(\bar{f}, w)}{c+Q(\bar{f}, w)}>\frac{Q(\bar{f}, w)-c}{Q(\bar{f}, w)} \\
& \Leftrightarrow 0>-c^{2} .
\end{aligned}
$$

We may now prove the Proposition: (1) $\left|T_{\mathrm{OFF}}^{\mathrm{S}}\right|=\int B\left(\tilde{b}^{\mathrm{S}}(w)\right) \mathrm{d} W$ $<\int B\left(\tilde{b}^{\mathrm{NS}}(w)\right) \mathrm{d} W=\left|T_{\mathrm{OFF}}^{\mathrm{NS}}\right|$ and $\left|T_{\mathrm{ON}}^{\mathrm{S}}\right|=1-\left|T_{\mathrm{OFF}}^{\mathrm{S}}\right|>1-\left|T_{\mathrm{OFF}}^{\mathrm{NS}}\right|=\left|T_{\mathrm{ON}}^{\mathrm{S}}\right|$; $\left|T_{\mathrm{I}}^{\mathrm{S}}\right|=\int \phi^{\mathrm{S}} B\left(\tilde{b}^{\mathrm{S}}(w)\right) \mathrm{d} W \quad<\int \phi^{\mathrm{NS}} B\left(\tilde{b}^{\mathrm{NS}}(w)\right) \mathrm{d} W=\left|T_{\mathrm{I}}^{\mathrm{NS}}\right|$ but $\left|T_{\mathrm{L}}^{\mathrm{S}}\right|=$ $\int\left[1-\phi^{\mathrm{S}}\right] B\left(\tilde{b}^{\mathrm{S}}(w)\right) \mathrm{d} W \gtrless \int\left[1-\phi^{\mathrm{NS}}\right] B\left(\tilde{b}^{\mathrm{NS}}(w)\right) \mathrm{d} W=\left|T_{\mathrm{I}}^{\mathrm{NS}}\right| ;(3)\left|\mathrm{OFF}^{\mathrm{S}}\right|=\int w\{1-$ $\left.\theta\left[1-\phi^{\mathrm{S}}(w)\right]\right\} B\left(\tilde{b}^{\mathrm{S}}(w)\right)<\int w\left\{1-\theta\left[1-\phi^{\mathrm{NS}}(w)\right]\right\} B\left(\tilde{b}^{\mathrm{NS}}(w)\right) \mathrm{d} W=\left|\mathrm{OFF}^{\mathrm{NS}}\right|$ and $\left|\mathrm{ON}^{S}\right|=[1-\theta] \int w\left[1-B\left(\tilde{b}^{\mathrm{S}}(w)\right)\right] \mathrm{d} W>[1-\theta] \int w\left[1-B\left(\tilde{b}^{\mathrm{NS}}(w)\right)\right] \mathrm{d} W=\left|\mathrm{ON}^{\mathrm{NS}}\right| ;$ (4) $\left|O F F_{\mathrm{I}}^{\mathrm{S}}\right|=\int w \phi^{\mathrm{S}}(w) B\left(\tilde{b}^{\mathrm{S}}(w)\right) \mathrm{d} W<\int w \phi^{\mathrm{NS}}(w) B\left(\tilde{b}^{\mathrm{NS}}(w)\right) \mathrm{d} W=\left|O F F_{\mathrm{I}}^{\mathrm{NS}}\right|$ but $\left.\left.\left|O F F_{\mathrm{L}}^{\mathrm{S}}\right|=[1-\theta] \int w\left[1-\phi^{\mathrm{S}}(w)\right] B\left(\tilde{b}^{\mathrm{S}}(w)\right)\right] \mathrm{d} W \gtrless[1-\theta] \int w\left[1-\phi^{\mathrm{NS}}(w)\right] B\left(\tilde{b}^{\mathrm{NS}}(w)\right)\right] \mathrm{d} W$ $=\left|O F F_{\mathrm{L}}^{\mathrm{NS}}\right|$.

Proof of Proposition 5 As the choices of investors in $T_{\mathrm{OFF}}$ make the tax authority indifferent between verifying and not-verifying (both with and without a scheme), it is straightforward to show that, in equilibrium, $R_{\mathrm{OFF}}^{\mathrm{S}}(y)=R_{\mathrm{OFF}}^{\mathrm{NS}}(y)=0$. Hence, using (5), we have

$$
R_{\mathrm{T}}^{k}=\iint_{\mathrm{T}_{\mathrm{ON}}^{k} \cup T_{\mathrm{L}}^{k}} \theta w \mathrm{~d} W \mathrm{~d} B=\theta \int w\left[1-\phi^{k}(w) B\left(\tilde{b}^{k}(w)\right)\right] \mathrm{d} W,
$$

where $k \in\{N S, S\}$. The result then follows from the inequalities in Proposition 3 .

Proof of Proposition 6 (1) Immediate from (2); (2) In equilibrium $C_{\mathrm{L}}=C_{\mathrm{I}}-\left[1+r_{\mathrm{OFF}}\right] \theta w$. Hence $C_{\mathrm{OFF}}\left(\phi^{k}\right)=\phi^{k} C_{\mathrm{I}}+\left[1-\phi^{k}\right]\left\{C_{\mathrm{I}}-\left[1+r_{\mathrm{OFF}}\right] \theta w\right\}$ $=C_{\mathrm{I}}-\left[1-\phi^{k}\right]\left[1+r_{\mathrm{OFF}}\right] \theta w$. It follows that $C_{\mathrm{OFF}}\left(\phi^{\mathrm{S}}\right)<C_{\mathrm{OFF}}\left(\phi^{\mathrm{NS}}\right) \Leftrightarrow \phi^{\mathrm{S}}<\phi^{\mathrm{NS}}$, where the right-side holds by Proposition 3; (3) As $C_{\mathrm{ON}}$ is unaffected by a scheme, investors who invest offshore in the absence of a scheme but switch to investing onshore in the presence of a scheme must switch to a lower payoff.

Proof of Proposition 7 Using the relationship $Q\left(f_{\mathrm{S}}, y\right)=\alpha_{\mathrm{S}} Q(\bar{f}, y)$ in $(11)$, and substituting $\alpha_{\mathrm{S}}=\underline{\alpha}_{\mathrm{S}}$ from (15), the result obtains.

\section{References}

Alstadsæter, A., Johannesen, N., \& Zucman, G. (2018). Who owns the wealth in tax havens? Macro evidence and implications for global inequality. Journal of Public Economics, 162(1), 89-100. 
Bayer, R.-C., Oberhofer, H., \& Winner, H. (2015). The occurrence of tax amnesties: Theory and evidence. Journal of Public Economics, 125(1), 70-82.

Bazart, C., Beaud, M., \& Dubois, D. (2014). On the efficiency of whistleblowing-based audit schemes to fight tax evasion: An experimental approach. Paper presented at the International Tax Analysis Conference, London.

Bethmann, D., \& Kvasnicka, M. (2016). International tax evasion, state purchases of confidential bank data and voluntary disclosures. Korea University discussion paper no. 1603.

Bigio, S., \& Zilberman, E. (2011). Optimal self-employment income tax enforcement. Journal of Public Economics, 95(9-10), 1021-1035.

Boesler, M. (2012). The controversial 'Lagarde List' has leaked, and it's bad news for the Greek prime minister. https://www.businessinsider.com.au/lagarde-list-of-swiss-bank-accounts-leake d-2012-10. Accessed 18 Dec 2019.

Bordignon, M. (1993). A fairness approach to income tax evasion. Journal of Public Economics, 52(3), 345-362.

Center for Public Integrity. (2013). Secrecy for sale: Inside the global offshore money maze. Washington, DC: Center for Public Integrity.

Chetty, R., Looney, A., \& Kroft, K. (2009). Salience and taxation: Theory and evidence. American Economic Review, 99(4), 1145-1177.

Chu, C. Y. C. (1990). Plea bargaining with the IRS. Journal of Public Economics, 41(3), 319-333.

Committee of Public Accounts. (2008). HMRC: Tackling the hidden economy, HC 712. London: The Stationery Office.

DEG. (2015). Annual report 2015: Financial statements and management report. DEG: Cologne.

Dharmapala, D. (2016). Cross-border tax evasion under a unilateral FATCA regime. Journal of Public Economics, 141(1), 29-37.

European Union. (2003). Council directive 2003/48/EC of 3 June 2003 on taxation of savings income in the form of interest payments. Official Journal of the European Union, L157, 38-48.

GAO. (2013). Offshore tax evasion: IRS has collected billions of dollars, but may be missing continued evasion, GAO-13-318. Washington, DC: Government Accountability Office.

Glen Ueng, K. L., \& Yang, C. C. (2001). Plea bargaining with the IRS: Extensions and further results. Journal of Public Economics, 81(1), 83-98.

Goerke, L. (2015). Income tax buyouts and income tax evasion. International Tax and Public Finance, 22(1), 120-143.

Graetz, M. J., Reinganum, J. F., \& Wilde, L. L. (1986). The tax compliance game: Toward an interactive theory of law enforcement. Journal of Law, Economics, and Organization, 2(1), 1-32.

Gravelle, J. G. (2009). Tax havens: International tax avoidance and evasion. National Tax Journal, 62(4), 727-753.

Hashimzade, N., Myles, G. D., Page, F., \& Rablen, M. D. (2014). Social networks and occupational choice: The endogenous formation of attitudes and beliefs about tax compliance. Journal of Economic Psychology, 40(1), 134-146.

Helm, R. W. (1997). Offshore investment funds. In C. E. Kirsch (Ed.), The financial services revolution: Understanding the changing role of banks, mutual funds, and insurance companies. Chicago: McGraw-Hill Education.

HMRC. (2006). HMRC annual report 2005-06. London: H.M. Revenue and Customs.

HMRC. (2012). Penalties for inaccuracies in returns and documents, CC/FS7. London: H.M. Revenue and Customs.

Johannesen, N., Langetieg, P., Reck, D., Risch, M., \& Slemrod, J. (2018). Taxing hidden wealth: The consequences of U.S. enforcement initiatives on evasive foreign accounts. NBER working paper no. 24366.

Johannesen, N., \& Stolper, T. B. M. (2017). The deterrence effect of whistleblowing-An event study of leaked customer information from banks in tax havens. Working paper of the Max Planck Institute for Tax Law and Public Finance no. 2017-4.

Johannesen, N., \& Zucman, G. (2014). The end of bank secrecy? An evaluation of the G20 tax haven crackdown. American Economic Journal: Economic Policy, 6(1), 65-91.

Kaplow, L., \& Shavell, S. (1994). Optimal law enforcement with self-reporting of behavior. Journal of Political Economy, 102(3), 583-606.

Kim, W., \& Wei, S.-J. (2002). Offshore investment funds: Monsters in emerging markets? Journal of Development Economics, 68(1), 205-224. 
Konrad, K. A., \& Stolper, T. B. M. (2016). Coordination and the fight against tax havens. Journal of International Economics, 103(1), 96-107.

Krishna, A., \& Slemrod, J. (2003). Behavioral public finance: Tax design as price presentation. International Tax and Public Finance, 10(2), 189-203.

Langenmayr, D. (2017). Voluntary disclosure of evaded taxes-Increasing revenue, or increasing incentives to evade? Journal of Public Economics, 151(1), 110-125.

Londoño-Vélez, J., \& Ávila-Mahecha, J. (2018). Can wealth taxation work in developing countries? Quasi-experimental evidence from Colombia. Paper presented at the Annual Congress of the IIPF, August 2018, Tampere.

Macho-Stadler, I., \& Pérez-Castrillo, J. D. (2002). Auditing with signals. Economica, 69(273), 1-20.

Mealem, Y., Tobol, Y., \& Yaniv, G. (2010). Whistle-blowers as a deterrent to tax evasion. Public Finance Review, 38(3), 306-320.

Oates, J. (2008). HMRC pays criminal for 'tax dodger' discs. https://www.theregister.co.uk/2008/02/26/ hmrc_disc_tax/. Accessed 18 Dec 2019.

OECD. (2010). Offshore voluntary disclosure: Comparative analysis, guidance and policy advice. Paris: Organisation for Economic Co-operation and Development.

OECD. (2013). Standard for automatic exchange of financial account information: Common reporting standard. Paris: Organisation for Economic Co-operation and Development.

O'Reilly, R. (2007). Complete guide to offshore bank accounts for funding online casino and poker play. Blackjack Forum, 26(1). http://www.blackjackforumonline.com/Complete_Guide_to_Offshore_ Bank_Accounts.htm. Accessed 18 Dec 2019.

Pfisterer, V. M. (2013). Walking a fine line-A contextual perspective on the purchase of "stolen" banking data by German authorities. German Law Review, 14(7), 926-948.

Pritchard, D., \& Khan, N. (2005). Offshore compliance: Using regression and risk modeling to select cases from large datasets. Paper presented at the IRS Research Conference, Washington DC.

Rablen, M. D. (2010). Tax evasion and exchange equity: A reference-dependent approach. Public Finance Review, 38(3), 282-305.

Rablen, M. D. (2014). Audit probability versus effectiveness: The Beckerian approach revisited. Journal of Public Economic Theory, 16(2), 322-342.

Sánchez, I., \& Sobel, J. (1993). Hierarchical design and enforcement of income tax policies. Journal of Public Economics, 50(3), 345-369.

Scotchmer, S. (1987). Audit classes and tax enforcement policy. American Economic Review, 77(2), 229-233.

Treasury Committee. (2012). Closing the tax gap: HMRC's record at ensuring tax compliance, HC 1371. London: The Stationery Office.

Watt, H., Winnett, R., \& Newell, C. (2012). HSBC investigation: Clients of Britain's biggest bank exposed. The Telegraph, 10th November. London: Telegraph Media Group.

Yaniv, G. (2001). Revenge, tax informing, and the optimal bounty. Journal of Public Economic Theory, $3(2), 225-233$.

Zucman, G. (2013). The missing wealth of nations: Are Europe and the U.S. net debtors or net creditors? Quarterly Journal of Economics, 128(3), 1321-1364.

Publisher's Note Springer Nature remains neutral with regard to jurisdictional claims in published maps and institutional affiliations. 